\title{
Rede de conhecimento sobre a produção quilombola de alimentos no
} IFSP Campus Registro: cultura e tradição alimentar

\section{Knowledge network on quilombola food production in the IFSP Registro}

Campus: culture and food tradition

\section{lamara de Almeida Nepomuceno Juliana Cesário Aragi ${ }^{2}$}

RESUMO: O Vale do Ribeira está entre as áreas de maior preservação da Mata Atlântica e, neste bioma, habitam cerca de 80 comunidades quilombolas que praticam a agricultura de coivara itinerante. O Sistema Agrícola Tradicional Quilombola (SAT) define-se por conhecimentos aplicados na agricultura de subsistência, na medicina, na cultura material e nas organizações de trabalho. Com iniciativas como o Programa Nacional de Alimentação Escolar (PNAE) e o Programa de Aquisição de Alimentos (PAA), existem melhores condições de manutenção dos meios e modos de vida das comunidades quilombolas, garantindo maior autonomia e a permanência na terra. Nesta pesquisa, buscamos compreender em que medida os esforços realizados pelo campus Registro do Instituto Federal de Educação, Ciência e Tecnologia de São Paulo (IFSP) em relação a esses programas podem ajudar na ampliação do conhecimento dessas tradições no âmbito institucional. Analisamos fontes orais, com base no método da História Oral, abordando-as a partir de conceitos de "identidade" e "memória", além de documentos produzidos para o reconhecimento do SAT como Patrimônio Imaterial Brasileiro (Dossiê SAT e Inventário Cultural Quilombola). Realizamos ainda projeto junto aos estudantes do quilombo de Sapatu, presentes no campus, o que resultou na aproximação dos demais alunos com a realidade quilombola, na valorização do consumo de alimentos in natura, sem agrotóxicos, e no estímulo a parcerias

\footnotetext{
${ }^{1}$ Mestra em História Social na Universidade de São Paulo. Contato: iamnepo@gmail.com.

${ }^{2}$ Mestranda em Nutrição na Universidade Federal de São Paulo. Contato: juliana.aragi@gmail.com.
} 
nos processos de compras institucionais de alimentos - um exemplo foi a banana fornecida em 2019 pelo PNAE, que adveio do referido quilombo.

Palavras-chave: povos tradicionais; quilombos; memória; agricultura; alimentação.

ABSTRACT: Ribeira valley is one the most preserved areas of the Atlantic Forest in Brazil. In this biome there are about 88 quilombola traditional communities that practice itinerant coivara agriculture. The Quilombola Traditional Agricultural System (SAT) is defined by knowledge applied in subsistence agriculture, medicine, material culture and work organizations. Initiatives like the National School Feeding Program (PNAE) and the Food Acquisition Program (PAA) provide better conditions for maintaining the livelihood of quilombola communities, ensuring greater autonomy and permanence on land. In this research, we seek to understand to what extent the efforts made by the Federal Institute of Education, Science and Technology of São Paulo (IFSP) related to these programs can help to expand the knowledge of these traditions at the institutional level. We analyzed oral sources based on the Oral History method, approaching them from the concepts of "identity" and "memory", besides using documents produced for the recognition of the SAT as Brazilian Intangible Heritage (the SAT Dossier, and the Quilombola Cultural Inventory). We also carried out a project with students from the Sapatu quilombo, present at the campus, and, as a result, the other students got closer to the quilombola reality; the consumption of fresh food without pesticides was valued; and partnerships were encouraged in the processes of institutional food purchases - as an example, the banana provided in 2019 by PNAE came from Sapatu quilombo.

Keywords: traditional communities; quilombos; memory; agriculture; food. 


\section{Comunidades quilombolas do Vale do Ribeira: trajetória de resistência}

O Vale do Ribeira está localizado na porção sul do estado de São Paulo e leste do estado do Paraná. Dentro de São Paulo, ocupa 10\% do território e está dividido em três subregiões: sub-litorânea, médio Ribeira e alto Ribeira. Dentro desta região existem comunidades quilombolas, indígenas, ribeirinhas, caiçaras e diversos grupos familiares que se dedicam à agricultura familiar, além de moradores das roças que compõem o quadro social das comunidades ditas "caipiras". A região do Vale do Ribeira está entre as áreas de maior preservação da Mata Atlântica, sendo que, dentro do remanescente desse bioma, estão localizados em torno de 88 comunidades quilombolas (RIBEIRO FILHO, 2015).

Como principal atividade de subsistência dos quilombos da região, encontra-se a agricultura de coivara itinerante, que possibilitou a resistência dessas comunidades até os dias atuais, através do manejo de recursos naturais presentes em seus territórios, o que permite que não tenham que depender inteiramente dos centros urbanos. Segundo o Instituto Socioambiental, o Sistema Agrícola Tradicional Quilombola (SAT) do Vale do Ribeira é "um conjunto de saberes e técnicas aplicados no cultivo de uma variedade de plantas utilizadas na alimentação, medicina e cultura material" (ANDRADE; KISHIMOTO, 2017, v. 1, p. 22).

O cultivo de mandioca, milho, feijão e arroz compõe a base alimentar dessas comunidades quilombolas desde o período colonial. A partir desta cultura alimentar, estruturaram-se modos de fazer o plantio, de colheita e de troca que se tornaram tradicionais dentro da comunidade. Neste sentido, foi em torno da relação com a terra que construíram sua cultura e desenvolveram os principais valores que regem, ainda hoje, seu cotidiano: o território como um bem coletivo.

Essas comunidades ocuparam os territórios ao longo do rio Ribeira de Iguape durante o período da escravidão, tendo sido fomentadas e estruturadas devido à formação de núcleos de mineração no Vale do Ribeira. Com o passar do tempo, os africanos que foram escravizados fixaram-se nas áreas de fácil acesso ao rio, mas afastadas dos centros de poderes coloniais. Os primeiros movimentos de ocupação colonial que implicaram a presença de africanos no Brasil remetem à primeira metade do século XVI, quando alguns portugueses com interesses na obtenção de recursos minerais percorreram o território, principalmente, 
em busca de ouro e prata. De fato, permaneceram e organizaram agrupamentos que se transformaram em vilarejos e, posteriormente, foram alçados pela administração colonial portuguesa ao status de vilas e freguesias (PAES, 2014). As vilas de Iguape, Xiririca ${ }^{3}$ e Ivaporunduva ${ }^{4}$ tornaram-se pontos importantes de mineração, entre os séculos XVII e XVIII, fato que culminou na ampliação da quantidade da população escravizada (PAES, 2007).

Dentro dos núcleos de mineração, tão logo ganharam fama, os exploradores ampliaram o tráfico de Angola, do Congo, de Moçambique e, provavelmente, de Guiné e escravizaram volumosa mão de obra africana sob intervenção direta da administração portuguesa, por causa dos minérios. Para realizar o gerenciamento da extração e a produção das barras de ouro e de prata, construíram a Casa de Oficina Real da Fundição de Ouro em Iguape, na primeira metade do século XVII. Nesta casa, o ouro era batido e transportado para a região onde hoje fica o município de Registro. Na casa de registro, o ouro era registrado e pesado e descontavam-se o dízimo e os impostos para a coroa portuguesa (CARRIL, 1997, p. 29-30).

No entanto, a decadência do ouro, causada não apenas pela presença reduzida da produção de gêneros alimentícios, como também pela descoberta do ouro em Minas Gerais, no século XVIII, levou à diminuição da produção aurífera e ao abandono das terras e das populações escravizadas por parte de muitos mineradores. Outros carregaram os trabalhadores consigo, tornando progressivamente inviável o trabalho nas minas do Ribeira. Com o fim das atividades ligadas à extração do ouro, a Casa de Fundição de Iguape encerrou seus trabalhos. Neste contexto, as populações negras já ocupavam diversos arraiais, em localidades como Iporanga, Apiaí, Ivaporunduva, Xiririca e Registro (CARRIL, 1997).

No século XIX, essas mesmas populações negras, muitas ainda escravizadas, plantaram o arroz que se tornara base da produção comercial do período, abastecendo o mercado interno e externo (CARRIL, 1997, p. 29-30). A exportação do arroz levou a uma nova fase de prosperidade econômica na região, que se tornou referência na produção, convergindo, assim, para a atração populacional de outros povos, como os imigrantes japoneses já no início do século XX.

\footnotetext{
${ }^{3}$ Xiri'rica significa, na língua tupi, rio com corredeiras velozes. Depois de se tornar freguesia, nominado por alusão ao rio afluente do rio Ribeira, esta região passou a ser chamada de Eldorado, em 1948 (PAES, 2007, p.18). ${ }^{4}$ Ivaporunduva foi grafado de diversas maneiras, entre outras, citamos: "Vupurunduba", "Cuapurunduba", "Ovapurunduba", "Ivaporundyba", "Ivaporundyva". Nome dado a um a um afluente do rio Ribeira, na língua tupi, significa rio com muitos frutos (PAES, 2007, p.19).
} 
A busca pelo ouro fez surgir vilarejos onde o tráfico realizado por portugueses trouxe, forçosamente, a presença africana para o Vale do Ribeira. Mas a luta pela sobrevivência e a dedicação contínua para manter a vida de seus próximos manifestaram-se na criação de formas de resistências a situações de violência e ausência de liberdade: os quilombos. No Vale do Ribeira, eles nasceram dessa luta constante pela vida e pela permanência na terra, sobrevivendo e criando formas de viver a partir dela, adotando-a como sua quando nada mais era possível.

\section{Processo de reconhecimento do Sistema Tradicional como patrimônio}

O processo histórico que levou à presença africana no Vale do Ribeira foi o mesmo que proporcionou a conformação das formas de sobrevivência no território. O modo de produzir alimentos, seja por meio das roças, das técnicas de coivara ou de outras técnicas e valores sociais constituídos nesse processo, configurou uma cultura alimentar própria dessas comunidades. Este conjunto de elementos socioculturais estruturados a partir da roça foi designado como Sistema Agrícola Tradicional Quilombola (SAT).

Neste sentido, o SAT é o que norteia as relações e as organizações de trabalho, os contextos sociais de plantio, colheita e consumo dos produtos dentro das comunidades em que este meio de produção está presente. A existência e a preservação desta cultura se dão pela transmissão, baseada na oralidade, de geração em geração, dos conhecimentos, além do ensino presencial e prático dos mais jovens (ANDRADE; KISHIMOTO, 2017, v. 2).

A percepção de que este sistema constituía um bem cultural e, portanto, seria passível de ser patrimonializado figurou como uma estratégia de resistência e continuidade da permanência na terra. Neste sentido, registrar o "modo de fazer a roça" como um patrimônio oficializado, requerido ao Instituto do Patrimônio Histórico e Artístico Nacional (Iphan), foi uma "estratégia de ação em defesa dos territórios ocupados pelas comunidades quilombolas e de seus modos de vida tradicionais" (ANDRADE; KISHIMOTO, 2017, v. 1, p. 8).

Apesar de o Vale do Ribeira ter mais de 80 quilombos reconhecidos ou em processo de reconhecimento, apenas 19 comunidades entraram com o pedido de registro. Segundo Andrade e Kishimoto (2017, v. 1, p. 8), elas estão situadas em seis municípios do Vale do Ribeira e são as seguintes: Morro Seco (Iguape), Mandira (Cananeia), Abobral MargemEsquerda (Eldorado), Poça (Eldorado e Jacupiranga), Pedro Cubas (Eldorado), Pedro Cubas 
de Cima (Eldorado), Sapatu (Eldorado), André Lopes (Eldorado), Ivaporunduva (Eldorado), Galvão (Eldorado), São Pedro (Eldorado), Nhunguara (Eldorado e Iporanga), Piririca (Iporanga), Maria Rosa (Iporanga), Pilões (Iporanga), Bombas (Iporanga), Praia Crande (Iporanga), Porto Velho (Iporanga) e Cangume (Itaoca).

A agricultura de coivara é representante central do modo de fazer a roça, cujos elementos de destaque se caracterizam pela: "1) diversidade de espécies e variedades manejadas, sendo a maioria delas para fins alimentares; 2) rodízio das áreas de plantio; e por fim, 3) uso do fogo como técnica de abertura das clareiras e nutrição do solo" (ANDRADE; KISHIMOTO, 2017, v. 1, p. 23). A partir do relato abaixo, concedido em 2010 por Antoninho Ursulino, de 60 anos, do quilombo Bombas, vemos que há uma ancestralidade reconhecida no modo de fazer o plantio dos alimentos, cuja estrutura herdada organiza a vida e a cultura quilombola.

\begin{abstract}
A maior cultura nossa é a roça. Vem dos escravos. A gente passa machado onde os antigos já trabalhavam. Desde os 8 anos eu já puxava enxada, acompanhava os mais velhos desde pititiquinho. A roça de coivara é nossa tradição. Tem plantio de arroz, feijão, mandioca, milho, abóbora, cana, banana, mamão, amendoim, batata doce, laranja, limão, mexerica, ata, couve, alface, rúcula, escarola, almeirão, pepino, abóbora, chuchu, cará, inhame, beterraba, cenoura, alfavaca, cebolinha, salsinha e outros temperos, verduras e árvores frutíferas [...]. (URSULINO, apud ANDRADE; TATTO, 2013, p. 182)
\end{abstract}

O dossiê feito pelas referidas comunidades quilombolas que, em conjunto com o Instituto Socioambiental, solicitaram o registro desse sistema como patrimônio traz todos os procedimentos e técnicas desse sistema de plantação. Além disso, apresenta os valores apontados como sendo essenciais à cultura ligada ao SAT (ANDRADE; KISHIMOTO, 2017, v. 1-2). Os principais procedimentos relatados para a feitura das roças podem ser observados no trecho que segue:

As roças são feitas em clareiras abertas na floresta ou capoeira por meio de derrubada e uso do fogo, e após 3 a 5 anos de cultivo são deixadas em pousio. O tempo de pousio varia, mas é sempre maior que o tempo de cultivo. Durante o tempo de pousio, a área pode continuar sendo manejada ou ser abandonada. O cultivo é retomado quando a área apresenta vegetação lenhosa, ou seja, não antes de 7 a 10 anos. Antes desse período, a roça apresenta resultados insatisfatórios. (ANDRADE; KISHIMOTO, 2017, v. 1, p. 23) 
Para a execução desse sistema, há uma série de tarefas desempenhadas e distribuídas por pessoas da família: escolher área, carpir, cortar, limpar, plantar (na época da lua minguante) etc.; tudo isso compõe o rol de ações importantes para a produção e para a segurança alimentar. Como relata o já mencionado Antoninho:

Primeiro tem que roçar, picar a roça, passar a foice, plantar, carpir até o ponto de colher. Se for bastante, prepara o paiol. Conforme o tipo de plantio e colheita, o resultado muda: se tem muita chuva ou muito sol, pode ser fraco. Às vezes não dá para a despesa toda e às vezes colhe arroz de ficar atopetado. Quando a roça é longe, leva o almoço e come na roça: arroz, feijão, macarrão, batatinha, carne de porco ou de frango. Quando é perto, volta pra comer em casa. O paiol fica no meio da roça. Se a roça for pequena, o paiol é no terreno da casa e baldeia as coisas pra casa. Se tiver cangalha pra pôr no burro, põe no cesto de cargueiro. Se não põe no saco. Quando faz mutirão de colheita tem baile. Junta o povo, é o povo que faz a festa. Dança de par. Violão, sanfona, cavaquinho, pandeiro. Aqui só tem violão. O resto dos instrumentos os convidados trazem. Vamos pro poço tomar banho, pode tomar uma cachaça, depois vai jantar e iniciando na viola. (URSULINO, apud ANDRADE; KISHIMOTO, 2017, v. 1, p. 22)

Os manejos das sementes, bem como os arranjos produtivos locais, são feitos no seio das famílias, nas quais se reúnem cônjuges, filhos e, em alguns casos, agregados ou membros parentais de uma das partes. As crianças sempre são levadas para os espaços do roçado e, ali, brincam e aprendem, mas, nessa fase da vida, não exercem o trabalho de cultivo.

A questão da produção dos alimentos não encerrou em si mesma a importância da patrimonialização. Além de salvaguardar a tradição quilombola e o seu modo de vida, o pedido também possibilitou ampliar a luta pela soberania alimentar e pela manutenção das sementes crioulas, uma vez que aquele modo de fazer o plantio nos quilombos também garantiu a preservação de sementes sem alterações genéticas, que foram selecionadas com manejo sustentável dentre as mais produtivas e férteis.

O aceite do registro ocorreu no Rio de Janeiro, durante uma reunião no Forte de Copacabana, em setembro de 2018. Ali, o Conselho Consultivo do Iphan reconheceu como patrimônio, com unanimidade de votos, o Sistema Agrícola Tradicional (SAT) das Comunidades Quilombolas do Vale do Ribeira (SP). Neste mesmo mês, estávamos organizando o projeto "Quilombos de lá Quilombos de cá: uma vivência na horta escolar", visando à discussão sobre a importância de valorizar o modo de vida e de produção alimentar quilombola. Foi com grata surpresa que soubemos da patrimonialização do SAT e, com isto, ampliamos esse debate dentro do Instituto Federal de Educação, Ciência e Tecnologia de São 
Paulo (IFSP), no campus Registro, estendendo o referido projeto para as atividades do ano seguinte, inclusive intensificando o incentivo à aquisição de alimentos da agricultura familiar da região, principalmente, de origem quilombola.

Durante a execução desse projeto em 2019, percebemos que uma das grandes dificuldades enfrentadas pelas famílias produtoras da região estava relacionada ao escoamento da produção dos alimentos. Neste sentido, as políticas públicas ligadas à aquisição de alimentos da agricultura familiar mostraram-se relevantes para serem consideradas nas ações e contribuições do IFSP para as comunidades do Vale do Ribeira.

\section{As políticas públicas de incentivo à aquisição de alimentos da agricultura familiar}

O Programa Nacional de Alimentação Escolar (PNAE) tem como objetivo dar suporte às entidades de ensino público para o suprimento das necessidades nutricionais de seus alunos. Para isso, com o gerenciamento do Fundo Nacional de Desenvolvimento da Educação (FNDE), realiza o repasse, em caráter suplementar, de verba destinada para a compra de alimentos para as unidades executoras.

Iniciativas voltadas para a alimentação de estudantes ocorreram a partir da década de 1940, quando um "desjejum escolar" era ofertado, entretanto, apenas na década de 1950 é que um programa visando à alimentação escolar foi colocado em prática como política pública efetivamente, com o programa chamado de Campanha de Merenda Escolar. Neste sentido, as políticas públicas na área de segurança alimentar e nutricional, voltadas para a alimentação escolar, tiveram início efetivo na década de 1950 em parceria com a Organização das Nações Unidas para Agricultura e Alimentação. Porém, apenas em 1979 é que o programa passa a ser denominado PNAE. Em 1988 com a promulgação da Constituição Federal é assegurado o direito universalizado à alimentação escolar, para os estudantes de ensino fundamental da rede pública (PEIXINHO, 2013).

No ano de 2009, com a publicação da Lei n. 11.947, de 16 de junho de 2009, ocorre um grande avanço na abrangência do PNAE, pois universaliza o programa para toda a educação básica, além de incentivar o desenvolvimento sustentável, incentivando a compra de alimentos locais, respeitando a cultura e a tradição alimentar. Assim, para a efetivação destas diretrizes, a lei define a obrigatoriedade de que no mínimo 30\% dos recursos recebidos pelo 
PNAE sejam utilizados para a aquisição de gêneros alimentícios produzidos pela agricultura familiar (PEIXINHO, 2013; BRASIL, 2009).

Neste sentido, de valorização e ampliação das políticas públicas de segurança alimentar e nutricional, bem como de implantação da aquisição de compras da agricultura familiar, um marco importante foi a criação do Programa de Aquisição de Alimentos (PAA), criado pelo artigo 19 da Lei n. 10.696, de 02 de julho de 2003, com o intuito de promover 0 acesso à alimentação e incentivar a agricultura familiar (MDS). O PAA é constituído por seis modalidades: compra com doação simultânea, compra direta, incentivo à produção e ao consumo de leite, apoio à formação de estoques, compra institucional e aquisição de sementes (BRASIL, 2012).

Segundo Ghizelini (2018), com a iniciativa do PAA por parte do Estado e de instituições públicas, o interesse dos agricultores familiares aumentou, gerando a redução de seu tempo e trabalho nas atividades de monocultura especializadas e elevando o investimento nas áreas de produção diversificadas, como a horta, o pomar, os pequenos animais, a "agroindustrialização" artesanal, para a produção de alimentos in natura e minimamente processados - principal foco das aquisições pelo PAA.

Como forma de escoamento de produção, de subsistência e manutenção das comunidades tradicionais, o PNAE e o PAA são políticas públicas que possuem um papel importante, pois, como já dito, exigem alguma participação de produtos vindos da agricultura familiar na alimentação das instituições que os acessam. Assim, melhoram as possibilidades de manutenção dos meios e modos de vida dos produtores - as comunidades quilombolas, no caso aqui estudado-, garantindo maior autonomia e a permanência na terra (LOPES, 2017).

Nesta pesquisa, buscamos compreender em que medida os esforços realizados pela instituição de ensino em exceder esse valor mínimo proposto por essas políticas públicas podem ajudar na manutenção das tradições quilombolas quanto aos modos de produção e comercialização dos alimentos. Este questionamento se deu ao longo do desenvolvimento de uma horta no IFSP, campus Registro, em 2018, ligada ao já mencionado projeto "Quilombos de lá Quilombos de cá: uma vivência na horta escolar".

Desde então, estamos empreendendo esforços para a compreensão mais aprofundada do SAT quilombola, tentando dessa maneira garantir a ampliação do 
conhecimento sobre essas tradições no âmbito institucional, bem como a valorização e a manutenção da cultura quilombola no Vale do Ribeira.

\section{Uma educação interdisciplinar e a legislação sobre educação nutricional e ensino de cultura e história africana e afro-brasileira}

Com o aumento das doenças crônicas não transmissíveis e da obesidade em crianças e adultos, o Governo Federal instituiu a Lei n. 13.666, de 16 de maio de 2018, que altera a Lei de Diretrizes e Bases da Educação Nacional para incluir o tema transversal da educação alimentar e nutricional no currículo escolar e tentar reverter esses avanços, bem como assegurar informações sobre alimentação saudável aos cidadãos em idade escolar (BRASIL, 2018). Assim, segundo o Marco de Referência de Educação Alimentar e Nutricional (2012):

A prática da Educação Alimentar e Nutricional deve fazer uso de abordagens e recursos educacionais problematizadores e ativos que favoreçam o diálogo junto a indivíduos e grupos populacionais, considerando todas as fases do curso da vida, etapas do sistema alimentar e as interações e significados que compõem o comportamento alimentar. (BRASIL, 2012)

Desta forma, vislumbramos as interconexões entre a legislação que possibilita a promoção de uma educação alimentar saudável e a que assegura o ensino de História Africana e Afro-brasileira, em conformidade com a implantação da Lei n. 10.639, em 2003. Esta lei determinou que nas escolas de todo o país fossem ensinadas a história dos africanos e dos negros no Brasil em suas diferentes dimensões, em todas as disciplinas do currículo.

Neste sentido, se, por um lado, conseguimos desenvolver e promover o diálogo sobre o modo de vida sustentável do ponto de vista alimentar, também redimensionamos as perspectivas sobre a memória em torno da população quilombola, abrangendo aspectos positivos de sua presença no Vale do Ribeira e problematizando o racismo existente na sociedade que, por reiteradas vezes, a desumanizou por ser afrodescendente e por viver a territorialidade de maneira diferente à dos princípios capitalistas.

A perspectiva da perda de memória, por conta da imposição dos parâmetros técnicos de mercado, fez com que as produções locais e seus conhecimentos passados entre gerações tivessem um apagamento. No entanto, mesmo com estas delimitações mercadológicas, vemos as comunidades tradicionais lutarem por seus territórios de direito e se reinventarem 
com a reativação de seus conhecimentos, para poderem enfrentar os desafios impostos pela modernização (TOLEDO; BARRERA-BASSOLS, 2015).

Uma vez que os agricultores quilombolas são responsáveis pela produção de alimentos de forma tradicional, sobretudo, a partir da reprodução de um conhecimento perpetuado há gerações, com produções que possuem mais de um tipo de cultivo, eles também favorecem a manutenção das culturas alimentares tradicionais, além de assegurar que sementes originais e sem transformações genéticas permaneçam existindo e, assim, garantam a preservação em casos, por exemplo, de danos causados por mudanças climáticas ou pragas (ALTIERI, 2012).

Ao incluir a temática étnico-racial como item obrigatório do currículo escolar da educação básica, as Diretrizes Curriculares Nacionais para a Educação das Relações ÉtnicoRaciais rompem este ciclo de silenciamento ao deslocar a temática racial da esfera privada para a pública. A premissa fundamental sustenta que novas subjetividades - construídas através do conhecimento da História e da Cultura Afro-Brasileira e Africana - têm o poder de construir novas sociabilidades (BRASIL, 2004).

Assim, conforme denunciaram as Diretrizes, problematizamos o fato de que, muitas vezes, é na trajetória escolar que as crianças e os adolescentes, negros e não negros, vivenciam institucionalmente esse silenciamento, logo aprendendo a naturalizá-lo. Os privilégios e as desvantagens raciais se manifestam nas relações entre educadores e educandos, no currículo, nos materiais didáticos, na hierarquia dos trabalhadores da escola etc., naturalizando-se no vácuo construído pelo silenciamento (LUIGI, 2015).

Buscamos atuar neste vácuo, preenchendo-o com outras perspectivas sobre as comunidades quilombolas e suas formas de ser e estar no mundo, apresentando-as com uma roupagem mais realista e antirracista. Há nesta intenção uma profunda relação com a proposição de Abdias Nascimento (2009), para quem o quilombismo é uma continuidade da ancestralidade africana na sociedade brasileira. Assim, o

[...] conhecimento científico de que os afrodescendentes necessitam é aquele que os ajude a formular teoricamente - de forma sistemática e consistente - sua experiência de quase quinhentos anos de opressão. Haverá erros ou equívocos inevitáveis na busca de racionalidade do nosso sistema de valores, no esforço de definição de nós mesmos e de nosso caminho futuro. Não importa. Durante séculos temos carregado o peso dos crimes e dos erros do eurocentrismo "científico", seus dogmas impostos em nossa carne como marcas ígneas da verdade definitiva. 
Agora devolvemos ao obstinado segmento "branco" da sociedade brasileira suas mentiras, sua ideologia de supremacismo europeu, a lavagem cerebral que pretendia tirar nossa humanidade, nossa identidade, nossa dignidade, nossa liberdade. Proclamando a falência da colonização eurocêntrica, celebramos o advento da libertação quilombista. (NASCIMENTO, 2009, p. 206)

Para a elaboração do presente trabalho, foi realizado um levantamento bibliográfico e consulta em fontes históricas, além de experiências vivenciadas dentro do projeto de horta escolar desenvolvido com os conhecimentos quilombolas no IFSP Registro. Tomamos como base para análise inicial os documentos produzidos para o reconhecimento do SAT quilombola do Vale do Ribeira como Patrimônio Imaterial Brasileiro pelo Iphan, bem como os inventários culturais produzidos para a demarcação e a titulação das terras quilombolas.

Nesta seleção estão abarcados diferentes tipos de documentos, como entrevistas, fotos, desenhos, o registro de relatos da atividades realizadas pelos integrantes das comunidades quilombolas da região e um conjunto de informações sobre o que produzem e como produzem os alimentos, quais materiais e ferramentas são envolvidos nessas tarefas e relacionados aos modos tradicionais de fabricação de utensílios.

A coleta e a análise dos dados foram obtidas considerando a particularidade do tema abordado, a agricultura quilombola. Neste sentido, optou-se pela pesquisa qualitativa a fim de compreender e perscrutar o significado que manifestaram as comunidades quilombolas sobre sua cultura e os problemas sociais vivenciados.

Assim, percebemos que não conseguiríamos nos desviar da abordagem desta temática sem utilizarmos os conceitos de "memória" e "identidade". Bem como, para fins de análise do Dossiê SAT (ANDRADE; KISHIMOTO, 2017, v. 1-2) produzido pelo Instituto Socioambiental e do inventário cultural, poderíamos nos valer da análise das fontes com base no método de análise da História Oral. Neste sentido, consideramos que esses relatos são fontes documentais e, portanto, passíveis de interpretação, análise e crítica e, com isto, pretendemos situar historicamente os relatos contidos no dossiê e no inventário cultural a fim de construir vínculos com as comunidades quilombolas do Vale do Ribeira (MATOS; SENNA, 2011).

Tomamos a perspectiva das identidades no sentido proposto pelo filósofo Kwame Anthony Appiah, que as entende como complexas e múltiplas, brotando de uma história de respostas mutáveis às forças econômicas, políticas e culturais, quase sempre em oposição a outras identidades. 
Neste sentido, afirma que "toda identidade humana é construída e histórica [...]; cada qual é uma espécie de papel que tem que ser roteirizado, estruturado por convenções de narrativa a que o mundo jamais consegue conformar-se realmente" (APPIAH, 1997, p. 243). Também a memória é construída socialmente e está, assim como a identidade, em constante disputa social e intergrupal. A memória é "um elemento constituinte do sentimento de identidade, tanto individual como coletiva" e está diretamente relacionada à maneira como os indivíduos ou grupos sociais configuram a construção ou a "reconstrução de si" (POLLAK, 1992, p.5).

Dentro desta perspectiva, para fazer o aprofundamento proposto, tomamos como base, para estudo de caso, o mencionado projeto de extensão de construção de uma horta escolar desenvolvida por meio de conhecimento e prática da agricultura tradicional quilombola dentro do IFSP Registro. À época, havia dentro da instituição alunos quilombolas, que foram bolsistas. Para a implantação da horta foram realizadas atividades com representantes do quilombo de Sapatu e com os alunos, que também eram do mesmo território. Assim, foram desenvolvidos diálogos e eventos para a formação e a aplicação prática dos conhecimentos para a criação da horta dentro da instituição. Os conhecimentos foram passados de forma oral e prática durante as atividades realizadas ao longo do projeto, correspondendo à forma como os ensinamentos são passados dentro do próprio Sapatu, segundo relato dos representantes que conduziram as atividades.

Os quilombolas que participaram da atividade nos apresentaram um recorte de suas histórias. Indicaram que passaram por um processo conflituoso com as novas políticas ambientais, cujos enfrentamentos desgastaram a relação culturalmente instituída com o território. Estes processos de enfrentamento também foram relevantes na memória de Gilberto das Neves Motta, que, em 2011, aos 36 anos, concedeu entrevista sobre sua vivência no quilombo São Pedro:

Trabalho na terra faz bastante tempo, comecei a trabalhar com 8 anos de idade, mesmo estudando. Aprendi com meu pai, minha mãe. 0 meu sustento vem dali. Não é todo ano que eu planto, só quando sai licença. Agora vai sair uma licença de cinco anos, aí a gente vai poder fazer roça esse tempo todo. Antes era pro ano. Antigamente era feito mutirão grandão pra colher, agora faz mais não é aquele mutirão de antigamente. Eu mesmo não participei desse mutirão grande. Aí faz pilha de arroz e deixa guardado dentro de casa. Faz uma tarimba no paiol e vai colocando o arroz, o arroz dura até um ano. Infelizmente agora poucos tão plantando, por dois critérios: o meio ambiente e pelo outro, que eu vejo, é falta de 
interesse de algumas pessoas. Eles tão entrando em outro setor de outros serviços, plantando outras coisas como o palmito pupunha. (MOTTA, apud ANDRADE; TATTO, 2013, p. 186)

Outro ponto importante, mencionado pelo representante de Sapatu durante a atividade, foi o fato de que eles têm necessidade de obter licença ambiental para realizar o plantio. Indicaram que este fator dificultou a manutenção das práticas agrícolas e também levou os agricultores quilombolas a fazer empréstimos rurais nos bancos ou a se empregar em fazenda de terceiros. No trecho que segue, com parte do depoimento que Bonifácio Modesto Pereira concedeu em 2010, aos 85 anos, sobre o quilombo Morro Seco, vemos o impacto deste processo na vida dos quilombolas, principalmente daqueles que tentaram continuar a plantar.

Tenho relação com essa atividade desde que tenho 8 anos. A razão é que nós não tínhamos outra coisa pra se ocupar, como por exemplo, a escola. A carpição deve ser feita antes e depois de já ter planta na roça. Isso porque o mato afoga a plantação. Plantava com o chucho. O espaçamento da cova dependia do que íamos plantar. Se fosse feijão ou arroz, o espaço é de 25 $\mathrm{cm}$, um ao lado do outro. Sendo milho ou rama de mandioca, $1,5 \mathrm{~m}$ meio de uma cova pra outra. Banana era de $1,5 \mathrm{~m}$ a $2 \mathrm{~m}$. Naquele tempo não tinha nenhum recurso. $\mathrm{O}$ que se aproveitava da colheita, vendia. O que sobrava era pra garantir a manutenção do período de trabalho. Havia estratégia que alguns produtores tinham, como armazém para acertar na época da produção. O que eu fazia é o que ainda faço: carpir, plantar, roçar, tudo quanto é atividade na prática de fazer roça. Fazia apenas o sinal da cruz, para princípio e fim do trabalho. A principal razão da mudança é o seguinte: todo trabalhador rural praticante de roça deixava parte da produção para sua manutenção. Eles não souberam praticar o empréstimo e perderam crédito na agência bancária. Os comerciantes que forneciam produtos alimentícios alegaram que não poderiam vender mais a prazo, aí a chance do pequeno produtor se acabou. $O$ pequeno produtor pensou, então, em trabalhar de empregado. Aí apareceu a mudança, deixou a roça pra trabalhar de empregado. É importante para a comunidade porque além de gerar renda, ela colabora com a manutenção do que precisamos. Em segundo lugar, porque tudo o que se colhe é muito mais saudável do que o que se comprar fora. (PEREIRA, apud ANDRADE; TATTO, 2013, p. 186)

Com isto, houve um processo de desgaste e até mesmo de desvalorização do modo de cultivar e das práticas culturais dele derivadas. Esse sentimento de desmotivação também foi mencionado pelos jovens quilombolas que compunham o projeto, mas eles narraram sobre como os mais velhos e jovens se organizaram para enfrentar essas dificuldades. Esperança Santana Ramos Rosa, que deu seu depoimento sobre o quilombo Sapatu em 2011, 
aos 66 anos, trazia essa narrativa avivada em sua memória, assim como o gosto que comer o que se plantava com suas próprias mãos proporcionavam à sua família e a si mesma.

\begin{abstract}
Algumas pessoas ainda plantam em Sapatu, mas a maioria parou porque acha que é muito demorado e dá trabalho. Eles não podem mais roçar uma roça boa. Também porque as pessoas não podem fazer roça. Essa roça de capoeira e capinzal, que é a que pode roçar, é uma terra cansada já. Então desanimou bastante.

A minha família planta arroz, não bastante, porque não temos mais muita força. A gente planta uma quantia que dá pra gente cuidar. Eu gosto mais do arroz pilado em casa do que o da máquina. Tem mais vitamina e até $o$ gosto é diferente. (ROSA, apud ANDRADE; TATTO, 2013, p. 224)
\end{abstract}

Esse contexto despertou na comunidade a necessidade de reavivar a memória e a identidade em torno dos processos de plantio, o que mobilizou muitos membros para o pedido de patrimonialização, conforme exposto anteriormente. Mas o que chamou nossa atenção foi que, frente a esse conflito, houve o reagrupamento social para reavivar a cultura em torno do modo de produzir esses alimentos a partir da roça, com os "puxirões" (mutirões para o plantio de forma coletiva, em grande escala). Desta forma, percebemos que reside aí, na reconstrução da roça por meio do processo de patrimonialização, a importância da memória e da identidade nas perspectivas apontadas. Uma identidade que seria "complexa e múltipla", estruturando-se a partir das necessidades da concretude da realidade.

No aporte documental para o reconhecimento do SAT, encontramos relatos que expõem marcadores de identidade, heranças deixadas pelos antepassados, como o de Alcino Miranda, do quilombo Porto Velho, que concedeu seu depoimento em 2011, aos 62 anos, e descreveu o uso da moenda na produção do açúcar e da rapadura a partir do cultivo da cana. Fica evidente a indicação de processos de transformação sofridos com o andamento das questões ambientais, mas também com o acesso a outros maquinários utilizados para as atividades do roçado, como, no caso, o motor elétrico. Ainda assim, as permanências também se mostram em diferentes dimensões do plantio, a exemplo da produção de alimentos derivados da cana para comercialização nas feiras locais.

Acho que deve ser desde a época dos escravos ou desde que os portugueses chegaram no país. Aprendi vendo o meu pai trabalhar, quando tinha 20 anos, aqui mesmo na comunidade. Fiz todos os anos até 2007. Sempre usei a cana da minha própria plantação, usava o meu próprio dinheiro para comprar coisas que faltavam para os doces como laranja, mamão; farinha de mandioca para fazer a taiada. É colocar o 
melado nos litros e os doces no saquinho e depois vender na feira. A maior mudança que teve foi nos equipamentos, que antes a moenda funcionava com ajuda de cavalos e hoje ela já é uma moenda com motor elétrico. (MIRANDA, apud ANDRADE; TATTO, 2013, p. 231)

Localizado no município de Eldorado, o quilombo de Sapatu foi formado por negros que se reagruparam ali depois de terem rejeitado o recrutamento forçado para combater na Guerra do Paraguai, por volta de 1870, e também por famílias vindas de outras comunidades da região em busca de terras para uso e moradia (ANDRADE; KISHIMOTO, 2017, v. 1, p. 377). Assim como nos demais territórios quilombolas, enfrentam uma série de desafios para permanecer no território. O principal deles foi a manutenção da roça como elemento central da vida.

No decorrer do projeto, ampliamos o espaço de diálogo sobre a história e a cultura quilombola no IFSP e ainda aprendemos os processos de produção de alimento no SAT, valorizando, com isso, os conhecimentos tradicionais. Mostramos que, apesar das dificuldades, eles continuam plantando e possuem como atividade de subsistência a comercialização de banana, palmito, arroz, feijão, milho e inhame, além da produção para o consumo próprio.

Para o escoamento dos produtos voltados para a comercialização, os lavradores participam de programas como o PNAE e o PAA, através de cooperativas e sindicato. Assim, após a aproximação do quilombo com o IFSP, durante o desenvolvimento do projeto, a banana fornecida pelo PNAE em 2019 para os alunos foi aquela produzida em Sapatu. Além disso, o restante da verba se direcionou à chamada pública destinada, nesse caso, para a compra da agricultura familiar local.

\section{Resultados e considerações finais}

Verificamos diferentes resultados do projeto de extensão da horta. Entre eles, mencionamos a aproximação dos alunos com a realidade quilombola e com os colegas quilombolas que estudam no IFSP, o estímulo ao importante consumo de alimentos in natura e sem agrotóxicos e a abertura de diálogo da instituição com outros órgãos que incentivam a produção de hortas escolares, como, por exemplo, a prefeitura do município de Registro. Além disso, o projeto estimulou a demanda por mais estudos sobre a temática e aproximou a comunidade de Sapatu da instituição. 
Possibilitamos o acesso dos estudantes aos conhecimentos sobre o Sistema Tradicional Agrícola Quilombola, por meio de palestras e da vivência de plantio guiada por quilombolas no campus. Com o projeto, foi possível abordar temas ambientais de maneira ampla e prática junto aos participantes, uma vez que trabalhamos com a terra e vimos de que maneira o cuidado com ela se dá, baseado em ensinamento ancestral e transmitido de geração em geração dentro das comunidades. Os envolvidos também puderam observar a diferença entre uma roça cultivada nas comunidades tradicionais e as hortas convencionais, visualizando como é possível a produção de alimentos sem a utilização de produtos químicos.

Assim, a manutenção e a utilização dos costumes alimentares e de outras tradições ancestrais não são nem devem ser compreendidos somente como atos ideais, realizados pelas comunidades quilombolas como culto aos seus antecessores. Estas práticas constituem a própria forma encontrada pelas populações tradicionais para perpetuar sua vida, sua produção e sua reprodução social, de modo sustentável. Em outras palavras, tais práticas são os requisitos para a existência, a sobrevivência e a conservação dessas comunidades como territórios possuidores de identidade própria. A dificuldade é conseguirem se desvencilhar do estigma social ao qual estão associadas, deixando de ser invisíveis perante a sociedade e saindo da posição historicamente construída de subalternidade, para se integrarem à vida social em condições de igualdade, dignidade e cidadania. Isso somente poderá ser alcançado se houver garantias de preservação de seus territórios étnico-culturais, de suas práticas produtivas e alimentares e, enfim, de sua ancestralidade (ARAÚJO; LIMA FILHO, 2012).

Por fim, com o estudo e a aplicação no projeto de extensão, pudemos verificar que, com atividades que aproximam e valorizam as práticas das comunidades tradicionais, dentro da instituição de ensino, conseguimos criar vínculos entre os estudantes do campus e a realidade da produção de alimentos em sua complexidade. Também conseguimos aproximar as comunidades das práticas da instituição de ensino, criando parcerias nos processos de compras institucionais de alimentos, cuja possibilidade de ampliação pode contribuir com a manutenção dos processos de produção. E pode também colaborar com o fortalecimento de sua identidade perante órgãos institucionais e sociais, assim como culminar com garantia da política de permanência estudantil dentro do IFSP, para os estudantes quilombolas. 


\section{Referências}

ALTIERI, Miguel. Agricultura familiar camponesa como patrimônio ecológico planetário. In: ALTIERI, Miguel. Agroecologia: bases científicas para uma agricultura sustentável. São Paulo/Rio de Janeiro: Expressão Popular/AS-PTA, 2012 [2008], p. 363-378.

ANDRADE, Anna Maria; TATTO, Nilto (ed.). Inventário cultural de quilombos do Vale do Ribeira. São Paulo: Instituto Socioambiental, 2013.

ANDRADE, Anna Maria de Castro; KISHIMOTO, Alexandre (org.). Dossiê Sistema Agrícola Tradicional Quilombola do Vale do Ribeira. V. 1. São Paulo: Instituto Socioambiental, 2017.

ANDRADE, Anna Maria de Castro; KISHIMOTO, Alexandre (org.). Dossiê Sistema Agrícola Tradicional Quilombola do Vale do Ribeira. V. 2. São Paulo: Instituto Socioambiental, 2017.

APPIAH, Kwame Anthony. Identidades africanas. In: APPIAH, Kwame Anthony. Na casa de meu pai. Rio de Janeiro: Contraponto, 1997.

ARAÚJO, Maria do Socorro Gomes; LIMA FILHO, Domingos Leite. Cultura, trabalho e alimentação em comunidades negras e quilombolas do Paraná. Ateliê Geográfico, v. 6, n. 3, p. 113-131, 2012. Disponível em: https://doi.org/10.5216/ag.v6i3.21060. Acesso em 29 jul. 2020.

BRASIL. Lei n. 10.639, de 9 de janeiro de 2003. Altera a Lei n. 9.394, de 20 de dezembro de 1996, que estabelece as diretrizes e bases da educação nacional, para incluir no currículo oficial da Rede de Ensino a obrigatoriedade da temática 'História e Cultura Afro-Brasileira', e dá outras providências. Diário Oficial da União: Brasília, DF, 10 jan. 2003. Disponível em: http://www.planalto.gov.br/ccivil_03/leis/2003//10.639.htm. Acesso em: 28 jul. 2020.

BRASIL. Resolução n. 1, de 17 de junho de 2004. Institui Diretrizes Curriculares Nacionais para a Educação das Relações Étnico-Raciais e para o Ensino de História e Cultura AfroBrasileira e Africana. Diário Oficial da União: seção 1, Brasília, DF, 2004, p. 11. Disponível em: http://portal.mec.gov.br/cne/arquivos/pdf/res012004.pdf. Acesso em: 28 jul. 2016.

BRASIL. Lei ${ }^{0}$ 11.947, de 16 de junho de 2009. Dispõe sobre o atendimento da alimentação escolar e do Programa Dinheiro na Escola aos alunos da educação básica. Diário Oficial da União: Brasília, DF, 17 jun. 2009. Disponível em: 
http://www.planalto.gov.br/ccivil_03/_At02007-2010/2009/Lei/L11947.htm. Acesso em: 28 jul. 2020.

BRASIL. Decreto n. 7.775, de 04 de julho de 2012. Regulamenta o art. 19 da Lei n. 10.696, de 2 de julho de 2003, que institui o Programa de Aquisição de Alimentos, e o Capítulo III da Lei $n^{0} 12.512$, de 14 de outubro de 2011, e dá outras providências. Diário Oficial da União: Brasília, DF, 5 jul. 2012. Disponível em: http://www.planalto.gov.br/ccivil_03/_Ato20112014/2012/Decreto/D7775.htm. Acesso em: 20 out. 2016.

BRASIL. Ministério do Desenvolvimento Social e Combate à Fome. Marco de referência de educação alimentar e nutricional para as políticas públicas. Brasília: MDS/Secretaria Nacional de Segurança Alimentar e Nutricional, 2012.

BRASIL. Lei $n^{0}$ 13.666, de 16 de maio de 2018. Altera a Lei $n^{0}$ 9.394, de 20 de dezembro de 1996

(Lei de Diretrizes e Bases da Educação Nacional), para incluir o tema transversal da educação alimentar e nutricional no currículo escolar. Diário Oficial da União: Brasília, DF, 17 mai. 2018. Disponível em: http://www.planalto.gov.br/ccivil_03/_Ato20152018/2018/Lei/L13666.htm. Acesso em: 05 mar. 2019.

BRASIL. Ministério da Cidadania. Secretaria Especial de Desenvolvimento Social (MDS). Programa de Aquisição de Alimentos (PAA). Instituído pelo art. 19 da Lei nº 10.696, de 02 de julho de 2003. Disponível em: http://mds.gov.br/assuntos/segurancaalimentar/programa-de-aquisicao-de-alimentos-paa. Acesso em: 05 out. 2018.

BRASIL. Ministério da Educação (MEC). Fundo Nacional de Desenvolvimento da Educação (FNDE). Programa Nacional de Alimentação Escolar (PNAE) - Histórico. Disponível em: $\quad$ https://www.fnde.gov.br/index.php/programas/pnae/pnae-sobre-oprograma/pnae-historico. Acesso em: 05 out. 2018.

CARRIL, Lourdes. Terras de negros: herança de quilombos. São Paulo: Scipione, 1997.

GHIZELINI, André A. Michelato. Programa de Aquisição de Alimentos e diversificação: possibilidades para a recampesinização e suas limitações estruturais. In: PEREZCASSARINO, Julian; TRICHES, Rozane Marcia; BACCARIN, José Giacomo; TEO, Carla Rosane Paz Arruda (org). Abastecimento alimentar: redes alternativas e mercados institucionais. Chapecó/Praia (Cabo Verde): Editora UFFS/ UNICV, 2018, p. 170-184.

LOPES, Heloísa. Cooperativismo quilombola, produção de alimentos e segurança alimentar no Vale do Ribeira. In: Anais Eletrônicos do XVI Encontro de Ceógrafos da América Latina, La Paz, 2017. 
LUIGI, André Santos. O ensino de História da África: interfaces entre a legislação federal e o currículo de História do estado de São Paulo. Dissertação (Mestrado em Educação) Universidade Federal de São Carlos. Sorocaba, 2015.

MATOS, Júlia Silveira; SENNA, Adriana Kivanski de. História oral como fonte: problemas e métodos. HISTORIÆ, Rio Grande, v. 2, n. 1, p. 95-108, 2011.

NASCIMENTO, Abdias do. Quilombismo: um conceito emergente do processo históricocultural da população afro-brasileira. In: NASCIMENTO, Elisa Larkin (org.). Afrocentricidade: uma abordagem epistemológica inovadora. São Paulo: Selo Negro, 2009.

PAES, Gabriela Segarra Martins. A 'recomendação das almas' na comunidade remanescente de Quilombo de Pedro Cubas. Dissertação (Mestrado em História Social) - Faculdade de Filosofia, Letras e Ciências Humanas da Universidade de São Paulo. São Paulo, 2007. Disponível em: https://doi.org/10.11606/D.8.2007.tde-01122009-160957. Acesso em 13 mar. 2018

PAES, Gabriela Segarra Martins. Ventura e desventura no Rio Ribeira de Iguape. Tese (Doutorado em História Social) - Faculdade de Filosofia, Letras e Ciências Humanas da Universidade de São Paulo. São Paulo, 2014. Disponível em: https://doi.org/10.11606/T.8.2014.tde-13052014-112252. Acesso em 16 mar. 2018.

PEIXINHO, Albaneide Maria Lima. A trajetória do Programa Nacional de Alimentação Escolar no período de 2003-2010: relato do gestor nacional. Ciência \& Saúde Coletiva, v. 18, n. 4, p. 909-916, 2013.

POLLAK, Michael. Memória e identidade social. Estudos Históricos, Rio de Janeiro, v. 5, n. 10, p. 200-215, jul. $1992 . \quad$ Disponível em: http://bibliotecadigital.fgv.br/ojs/index.php/reh/article/view/1941/108. Acesso em: 16 mai. 2019.

RIBEIRO FILHO, Alexandre Antunes. Impactos do sistema agrícola itinerante sobre os solos de remanescente de Mata Atlântica com uso e ocupação por comunidades quilombolas no Vale do Ribeira. Tese (Doutorado em Ciências na Área de Ecologia de Ecossistemas Terrestres e Aquáticos) - Instituto de Biociências da Universidade de São Paulo. São Paulo, 2015.

TOLEDO, Víctor M.; BARRERA-BASSOLS, Narciso. A memória biocultural: a importância ecológica das sabedorias tradicionais. São Paulo: Expressão Popular, 2015. 